\title{
Inovação no jornalismo brasileiro: o caso das reportagens multimídia TAB, do Uol
}

INNOVATION IN BRAZILIAN JOURNALISM: THE CASE OF MULTIMEDIA REPORTS TAB, OF UOL

\section{Mauro de Souza Ventura}

Coordenador do Programa de Pós-Graduação em Comunicação (Mestrado e Doutorado) da Universidade Estadual Paulista, campus de Bauru, e professor do curso de Jornalismo da Faculdade de Arquitetura, Artes e Comunicação da Universidade Estadual Paulista, Campus de Bauru.

E-mail: mauroventura@faac.unesp.br

\section{Liliane de Lucena Ito}

Pesquisadora bolsista Capes. Doutoranda em Comunicação pelo Programa de Pós-Graduação em Comunicação da Universidade Estadual Paulista.

E-mail: lilianedelucena@gmail.com

Recebido em 2 de dezembro de 2015. Aprovado em 9 de maio de 2016.

\section{Resumo}

Planejada para ser acessível em dispositivos móveis, resultados, está a catalogação de elementos constana série de reportagens multimídia $\mathrm{TAB}^{1}$ é um exemtes que levam a inferir sobre um distanciamento do plo de inovações aplicadas ao jornalismo. Este trabaformato padrão da webnotícia, uma vez que os textos lho buscou compreender o uso de diferentes elemensão mais longos, mas nem por isso enfadonhos, sentos narrativos (verbais, sonoros e visuais) que condo capazes de estimular uma leitura imersiva. ferem interatividade e hipertextualidade ao material. O corpus é composto por seis reportagens e, entre os

Palavras-chave: Reportagem multimídia. Novas narrativas. Webjornalismo.

1 Disponível em: <tab.uol.com.br $>$. 


\section{Abstract}

Planned to be available on mobile devices, the series of multimedia reports $\mathrm{TAB}$ is an example of innovation applied to journalism. This study aimed to understand the use of different narrative elements (verbal, auditory and visual) that provide interactivity and hypertextuality to the material. The corpus consists of six reports and within the results is the cataloging of constant elements that lead to infer a departure from the standard webnews format, since the texts are longer, but by no means boring, being capable of stimulating an immersive reading.

Keywords: Multimedia report. New narratives. Webjournalism.

\section{Introdução}

A sociedade contemporânea testemunha inovações na maneira de se contar uma história. Tais mudanças estão relacionadas ao momento de convergência midiática e de cultura de convergência (JENKINS, 2008) no qual todos estamos, de certa forma, imersos. No jornalismo, há a necessidade de busca por novos modelos de narrativa, uma vez que, principalmente na internet, ampliam-se os narradores (em grande parte não profissionais) e as plataformas onde é possível publicar conteúdos.

Deuze (2006) afirma que o avanço tecnológico e o acesso a dispositivos midiáticos estão relacionados às transformações no jornalismo. Fazer e receber notícias, produzir e consumir mídias, criar individual e colaborativamente são ações comuns e que crescem em larga escala por conta da adoção de tecnologias de informação e comunicação cada vez mais baratas, acessíveis e fáceis de serem utilizadas. Tudo isso resultou em novas formas de se narrar uma história, em que as preocupações do jornalista (mesmo os de veículos tradicionais) não se resumem a entregar a matéria formatada para apenas um meio.

Constantemente se fala sobre a crise no jornalismo (crise de valores, financeira ou mesmo sobre a credibilidade do jornalista), algo que, entretanto, pode ser confundida com um processo de transformação estrutural no jornalismo (PEREIRA; ADGHIRNI, 2011). Nesse novo cenário, que está em pleno andamento, há direcionamentos que podem ser observados no webjornalismo, como: a revisão de certos valores-notícia (PADILHA, 2012); a disjunção entre prática hipertextual e determinados critérios de noticiabilidade (VENTURA, 2009); a existência, além do gatekeeper, do gatewatcher, cujo desafio não é selecionar as notícias a ser encaixadas nas páginas de um jornal, mas, por conta da maior flexibilidade espacial de publicação na web, observar, 24 horas por dia, fontes primárias e a concorrência, a fim de publicar todo o conteúdo relevante para diversos públicos (BRUNS, 2005). 
Se vivemos um período de mudanças no jornalismo, certamente isso ocorre porque há também mudanças mais amplas, principalmente na maneira como o público lida com a informação. Como afirmam Pereira e Adghirni (2011), há, sim, um deslocamento dos leitores dos meios tradicionais (jornal impresso, por exemplo) para as mídias digitais, mas nada que sinalize o fim do jornalismo impresso. O que se transformaria, então, é a maneira como o leitor busca e consome a informação.

Dados estatísticos mais recentes de empresas jornalísticas apontam um crescimento importante no consumo de notícias digitais, algo que traz reflexos também para o modelo de negócios no jornalismo, que passa a focar em outras matrizes para a monetização da leitura. O modelo paywall (cobrança de acesso a conteúdos determinados) vem crescendo no País, e alguns títulos, como o jornal $O$ Globo, já comemoram lucratividades crescentes. $O$ Globo teve um aumento de $150 \%$ de sua base de assinantes digitais somente em 2014 (CORREIA, 2015), e cresce também a demanda por conteúdo para dispositivos móveis.

Os dirigentes do The New York Times, em junho de 2015, proibiram o acesso de seus funcionários da redação ao conteúdo do site do NYT por meio de desktops no ambiente de trabalho. Cada vez que o jornalista tentava acessar o conteúdo via computador de mesa, uma mensagem aparecia na tela pedindo que o acesso fosse feito via celular ou tablet. A ação, que num primeiro momento pode parecer banal ou sem muito sentido, teve o objetivo de conscientizar os jornalistas para a necessidade de criação cada vez mais expressiva de conteúdo voltado a dispositivos móveis, uma vez que $50 \%$ da audiência digital do The New York Times já é oriunda desse tipo de aparelho (O GLOBO, 2015). Esse tipo de ação vai ao encontro do que Canavilhas (2012) defende sobre o presente e o futuro do jornalismo:

No momento em que as empresas de comunicação social atravessam uma das piores crises de sempre, o aumento das taxas de penetração de smartphones e tablets pode constituir-se como uma fonte alternativa de receitas. A possibilidade de oferecer informação hipermultimediática, contextualizada e personalizada responde aos anseios manifestados pelos leitores quando questionados sobre o que os levaria a pagar informação online. Constitui, por isso, uma oportunidade para que as empresas possam cobrar o acesso às notícias. (CANAVILHAS, 2012, p. 16).

Em trabalhos mais antigos, mas ainda atuais em determinados aspectos, o autor faz análises sobre a característica hipermidiática do webjornalismo: possibilita a ascensão de novos modos de se narrar uma história (CANAVILHAS, 2001, 2006), marcadamente livres das amarras do espelho (do jornal ou da revista), do tempo (no caso do rádio e da 
televisão) ou ainda da escrita padrão do impresso, que prioriza textos objetivos, na qual os dados aparecem em ordem decrescente de importância, algo que por si só já estimula o leitor a se ater apenas aos parágrafos iniciais da matéria (TUCHMAN, 1993).

Já Longhi (2014) faz uma linha do tempo do jornalismo digital e afirma que, a partir de 2012, vive-se uma fase em que, além de aspectos técnicos de produção, novas características narrativas surgem. A narrativa jornalística do gênero que a autora defende como grande reportagem multimídia é de imersão no conteúdo, o chamado jornalismo long form, o que representaria um grande ganho de qualidade editorial.

Ao longo desses quase 15 anos de desenvolvimento de produtos noticiosos hipermidiáticos, os formatos também evoluíram, a ponto de se verificar, no cenário atual, um ponto de virada: momento de maturidade em que se estabelecem modos de fazer no que se configura como grande reportagem multimídia, onde características como design, narrativa e navegação se destacam, conferindo qualidade crescente a tais produtos. (LONGHI, 2014, p. 900).

Assim, é de grande importância compreender melhor quais são os elementos textuais, imagéticos, sonoros e de design que auxiliam na construção dessa nova narrativa jornalística, mais aprofundada e interpretativa, cujo pleno desenvolvimento e popularização ainda estão por acontecer, mas, certamente, representam uma quebra de paradigma na narrativa jornalística atual feita para circular na internet.

\section{Objetivo e metodologia}

Com o objetivo de realizar um estudo exploratório sobre reportagens multimídia, optou-se por analisar seis reportagens do TAB, veiculadas semanalmente, às segundas-feiras, no portal Uol. O TAB tem mostrado uma interface que combina elementos de impresso, rádio, TV e digital. Sua narrativa é hipermidiática e estimula a interatividade do público em muitos momentos, inclusive com a introdução de dados (input) do usuário. Segundo informações veiculadas pelo próprio Uol, as reportagens são disponibilizadas com destaque na home do portal às segundas-feiras, por ser o dia de maior audiência do site (UOL, 2014).

Patrocinado por apenas uma marca a cada edição, o TAB foi criado como um produto midiático que representasse, também, um novo formato comercial para o mercado anunciante, como afirmou o diretor de conteúdo, Rodrigo Flores, na ocasião de seu lançamento: "O TAB é a resposta do Uol para a necessidade do nosso público de consumir conteúdo de qualidade em formatos criativos, interessantes e interativos" (UOL, 2014). 
Até dia primeiro de dezembro de 2015, apenas duas marcas patrocinaram as 53 edições do TAB: a Vivo e a Jeep. A publicidade aparece em espaços fixos, de grande visibilidade, em duas ocasiões: a primeira, logo após o título da reportagem, mostra um vídeo de cinco segundos que precisa obrigatoriamente ser assistido para que seja possível acessar o restante do conteúdo; a segunda publicidade, com duração de aproximadamente um minuto, é colocada ora no meio das reportagens, ora ao seu final, não sendo obrigatório, entretanto, assisti-la para continuar a navegar pelo conteúdo do TAB.

As seis reportagens escolhidas foram: “1) Economia Compartilhada; 2) Fetiche pelo Vinil; 3) \#Não Me Representa; 4) Transgêneros; 5) Quem manda aqui; e 6) Identidade Digital"2. Justifica-se a escolha pela preferência por reportagens com características estruturais que representam a possibilidade de novas narrativas no webjornalismo. Assim, foram selecionadas aquelas que possuem uma grande variedade de recursos interativos e multimídia para catalogação e análise. As reportagens foram lidas observando-se aspectos referentes à linguagem e ao estilo jornalístico, e tais dados foram tabulados. Vídeos, áudios e elementos interativos também foram catalogados, e houve o registro dos elementos que mais se repetiam. Características gráficas comuns também foram buscadas e tabuladas. Ao final das observações, chegou-se aos principais elementos que constroem a narrativa do TAB, cuja descrição e discussão se darão a seguir.

\section{Resultados e discussão}

Nas seis reportagens analisadas, é possível observar o uso de certos elementos do formato noticioso padrão, como a presença de componentes visuais para destacar informações e "quebrar" o texto, a diferenciação entre título e subtítulos, e a indicação da fala do entrevistado entre aspas. Entretanto, a linguagem é muito mais livre, não obedecendo em nenhum dos casos ao formato da pirâmide invertida, em que as informações de maior relevância devem aparecer de maneira decrescente no texto. Consequentemente, não há lead encabeçando os textos. Tais características se relacionam, em primeiro lugar, ao gênero jornalístico do TAB, a reportagem, e aos temas escolhidos, que, em geral, não tratam de assuntos imediatos, urgentes, factuais.

2 Disponíveis em:

1) http://tab.uol.com.br/economia-compartilhada/

2) http://tab.uol.com.br/vinil/

3) http://tab.uol.com.br/democracia/

4) http://tab.uol.com.br/trans/

5) http://tab.uol.com.br/inconsciente/

6) http://tab.uol.com.br/senhas/

Acesso em: 30 maio 2015 
Salaverría (2005) cita três características da linguagem ciberjornalística: hipertextualidade, multimidialidade e interatividade, presentes em maior ou menor grau na narrativa do TAB. O autor afirma que o link é o elemento chave da redação para a internet, cuja função é conectar e organizar conteúdos multimídia distintos e traçar entre eles múltiplos itinerários de leitura. Entretanto, contrariamente aos textos noticiosos tradicionais (não importando sua extensão), a narrativa do TAB não traz links para notícias externas, sejam elas do próprio TAB ou do Uol. Não é possível, neste trabalho, afirmar a razão pela qual isso se dá, mas uma possibilidade é a de que a intenção seja realmente induzir a leitura concentrada, aprofundada, e não gerar cliques para outras páginas, mesmo as pertencentes ao grupo empresarial que mantém o TAB.

Apesar disso, o conteúdo poderia ser encaixado como hipertextual por haver uma divisão em blocos informacionais e em elementos multimídia que possibilitam uma leitura alinear das reportagens. Santaella (2004), ao explanar sobre o sistema hipertexto, diz: "Os nós são as unidades básicas de informação em um hipertexto [...] podem aparecer na forma de texto, gráficos, sequências de vídeos ou de áudio, janelas ou de misturas entre eles"(SANTAELLA, 2004, p. 49). A hipertextualidade pode, assim, ser claramente observada no caso da reportagem "Transgêneros", que possibilita que o leitor construa sua própria sequência de leitura. Logo depois do título e da publicidade, aparece uma tela com dois caminhos compostos de links internos: um direciona para a história de Letícia, com cinco links; e o outro para a história de Alexandre, com a mesma quantidade de links.

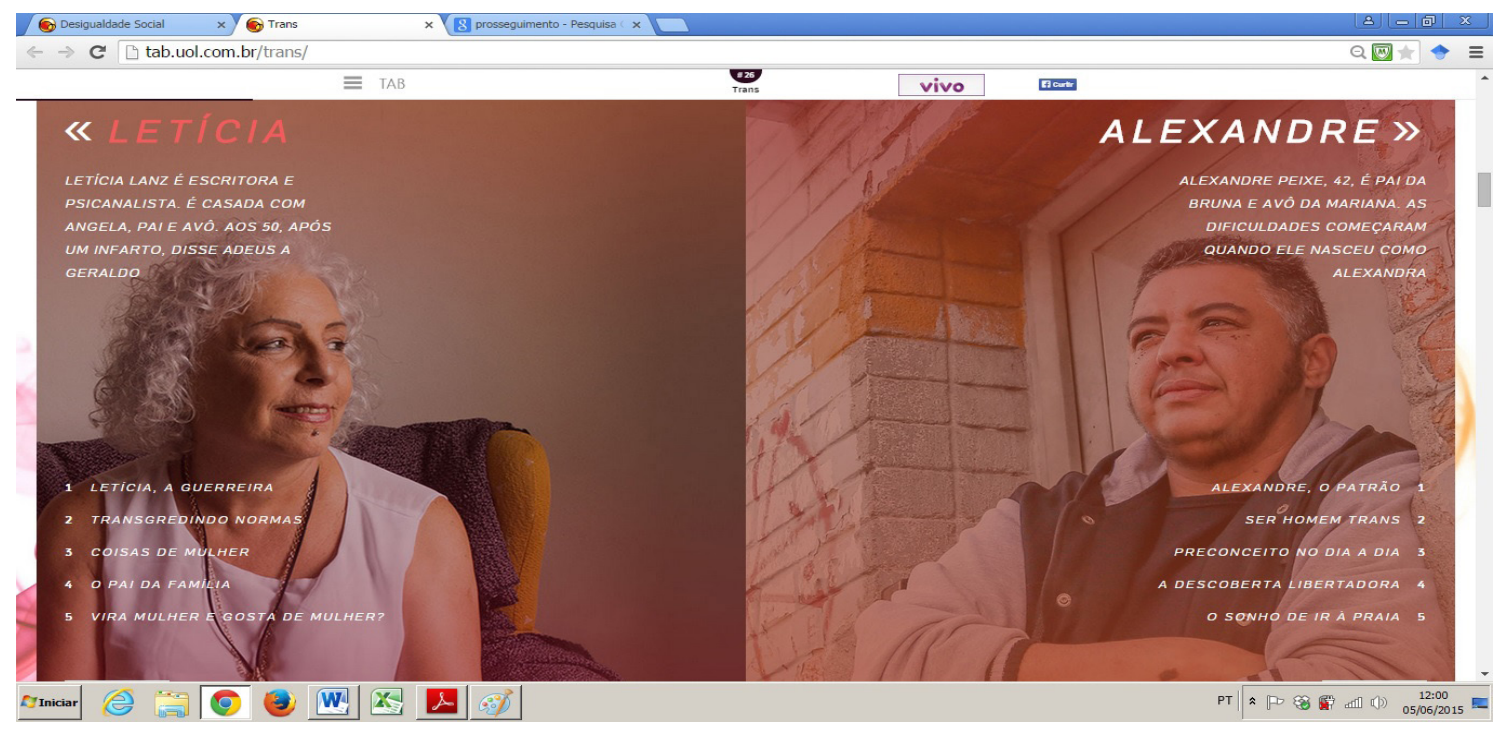

Figura 1. O hipertexto na reportagem "Transgêneros"

Fonte: http://tab.uol.com.br/trans/ 
A multimidialidade, por sua vez, é abundante em todas as reportagens, e, na amostra analisada, pode ser encontrada na forma de vídeos, áudios, infográficos animados e animações. A presença de elementos multimídia aprofunda o assunto tratado ou ilustra alguma ideia ou situação quando a narração puramente textual ficaria aquém do entendimento completo. Na amostra analisada, os vídeos aparecem mais constantemente (em cinco de seis reportagens), sendo bastante comum haver mais de um vídeo por reportagem. Os vídeos, que possuem duração, na maioria das vezes, de até três minutos e meio, contêm entrevistas ou até mesmo situações produzidas e roteirizadas pela equipe do TAB, com a finalidade de exemplificação.

Outro caso de multimidialidade da amostra analisada é a reportagem "Fetiche pelo Vinil", cujo texto pode ser lido ao som do áudio de cinco minutos que segue o formato dos podcasts. O narrador faz comentários e inclui sons que demonstram a diferença entre o som digital (de CDs) e o som do disco de vinil. O recurso é um exemplo de complemento informativo cuja função é muito mais contundente do que a explicação narrada somente via texto, uma vez que apresenta a materialidade do que está sendo tratado.

A mesma complementariedade informativa acontece no caso das animações, como na reportagem "Economia Compartilhada", em que uma animação de 35 segundos explica, por meio de desenhos, como se dá o seu funcionamento. Já em relação aos infográficos animados, o exemplo que mais se destaca está na reportagem "\#Não $\mathrm{Me}$ Representa", que mostra, em apenas uma tela que dispõe o mapa do mundo, todos os países que pertencem a diversos regimes de governo (democrático completo, democrático com falhas, híbridos e autoritários). A cada rolagem de tela feita para baixo, a fim de dar prosseguimento à informação, novos dados surgem enquanto desaparecem os anteriores, agrupados por cor, relacionando os sistemas governamentais aos países do globo.

Última das três características do texto ciberjornalístico apontadas por Salaverría (2005), a interatividade, também é explorada em todas as reportagens do TAB analisadas. Alguns exemplos estão na possibilidade de compartilhamento do conteúdo em redes sociais, de clicar em links para material multimídia interno à página, responder a enquetes sobre o tema da reportagem, preencher quizzes e testes (alguns com tempo para serem finalizados), além de jogos simples.

Da amostra analisada, dois elementos interativos se destacam pela maneira original como apresentam informações que, de certa forma, também são complementares ao conteúdo expresso na reportagem. Um se trata de um teste em que o usuário tem quatro chances para tentar descobrir determinada senha fictícia (uma vez que a reportagem "Identidade Digital" aborda questões relacionadas à segurança digital na contemporaneidade). O outro, da edição "\#Não Me Representa”, cujo tema versa sobre a democracia e 
a aparente insatisfação pública diante da política, oferece uma experiência interativa que complementa o conteúdo do texto ao levar o usuário a imaginar que pertence a determinado partido político e que foi eleito como presidente do país. A partir de informações sobre outros quatro partidos, deve-se tentar propor, dentro de um rol fixo de propostas determinadas pelo TAB, uma coalizão de governo. Em cada etapa do "jogo", informações adicionais sobre alianças políticas são dadas ao usuário. Abaixo, imagens ilustram os dois recursos interativos citados.

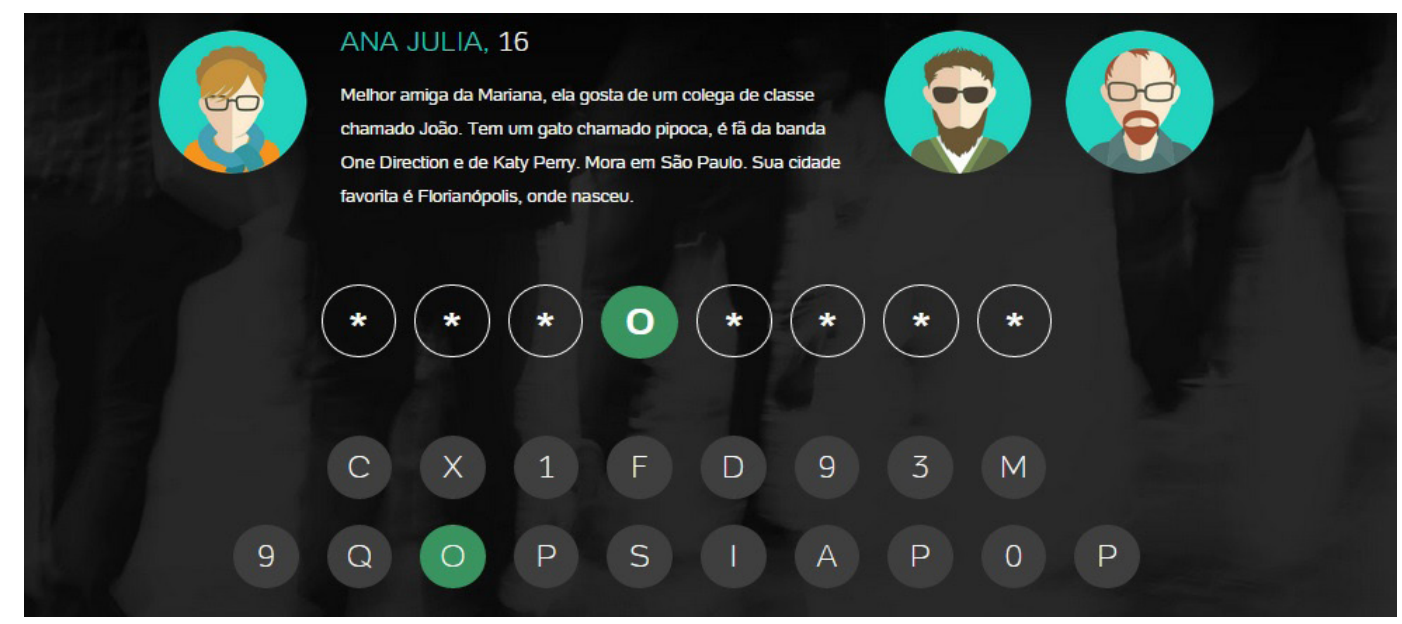

Figura 2. Interatividade no teste "Qual é a senha?"

Fonte: http://tab.uol.com.br/senhas/

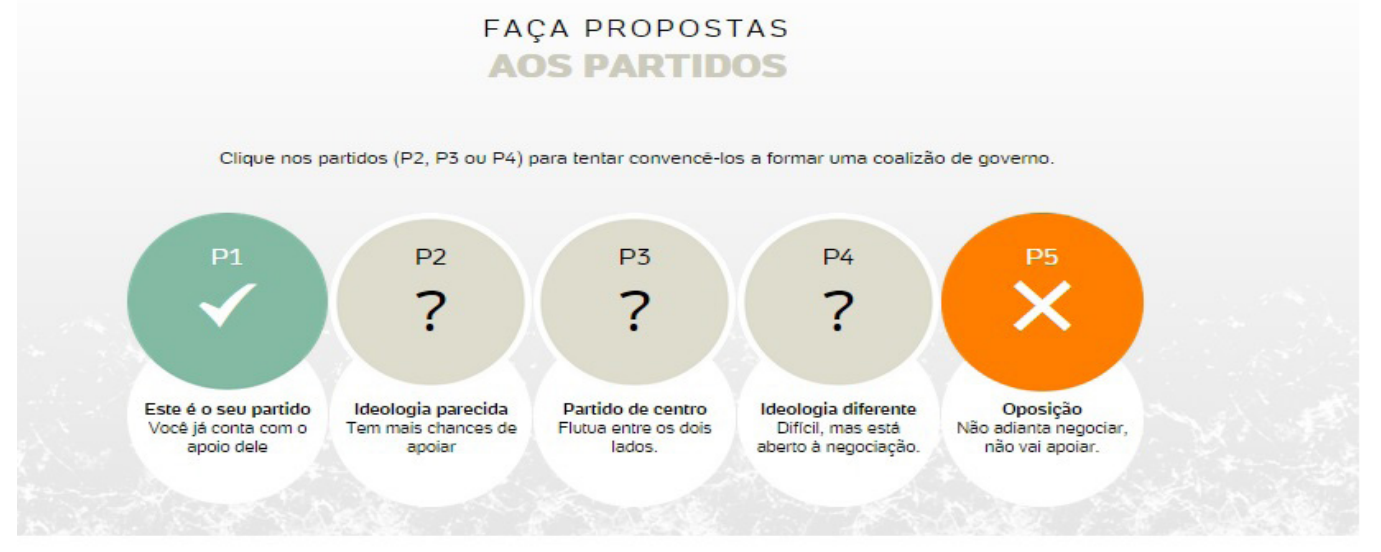

Figura 3. Interatividade no "Jogo da Coalizão"

Fonte: http://tab.uol.com.br/democracia/

$128 \frac{\text { Comunicação \& Inovação, PPGCOM/USCS }}{\text { v. 17, n. } 35 \text { (121-134) set-dez } 2016}$ 
É importante salientar que, apesar de interativas, as reportagens do TAB não oferecem espaços de interação mútua, em que há negociação relacional durante o processo (PRIMO, 2003). O tipo de interação existente no TAB é de caráter reativo, similar ao limiar estabelecido por Williams (1979) acerca dos videogames, nos quais a interatividade estabelecida é sempre muito baixa, uma vez que "embora solicitem respostas do jogador, essas respostas se dão sempre dentro de parâmetros que são as regras do jogo estabelecidas pelas variáveis do programa" (WILLIAMS, 1979 apud SANTAELLA, 2004, p. 154). Assim, apesar de haver recursos interativos, não há um nível de interação mais complexo, em que os usuários podem atuar como atores-criadores, como é o caso da interação mútua que ocorre em plataformas wiki ou fóruns de discussão.

\section{Layout: essencial para manter a atenção}

O layout das reportagens do $\mathrm{TAB}$ é produzido conforme o tema da edição, o que significa que o TAB apresenta maior liberdade em relação ao projeto gráfico de conteúdos jornalísticos do Uol. Em uma comparação com os veículos impressos, o TAB estaria mais próximo da estética dos suplementos especiais de jornais ou das revistas segmentadas, o que vai ao encontro de seu perfil editorial, pensado para oferecer novos formatos aos leitores do Uol. Assim, analisar a materialidade gráfica da reportagem pode evidenciar estratégias comunicativas: "o layout de uma publicação é conformado visando à comunicação, materializando, assim, um conceito editorial" (GRUSZYNSKI; CALZA, 2013, p. 218).

Cada edição é construída a fim de oferecer ao leitor uma experiência diferenciada de leitura e navegação. Para compor a identidade visual de cada tema, percebe-se que há uma produção imagética que visa a elaborar, com o texto, um material distinto do comum. Das seis reportagens analisadas, foi possível notar a presença de fotos, vídeos, ilustrações e infográficos (muitas vezes animados) especialmente produzidos para a edição, ou seja, que não foram retirados de outras fontes de informação ou de bancos de imagem. As fotos, em específico, não possuem um caráter factual, muito pelo fato de as reportagens não terem temáticas do tipo. Cores, formatos e tipografia (fontes, uso de negrito, caixa alta, entre outros) também variam conforme a estética planejada pelo designer para cada edição.

Mesmo com características semelhantes ao projeto gráfico de revistas/suplementos, há elementos novos no que se refere à apresentação da reportagem. Apesar da liberdade gráfica, todas as matérias publicadas pelo TAB obedecem a uma estrutura semelhante em seu início, compondo a identidade visual. Esse padrão envolve texto (o logotipo do TAB junto do título da reportagem em questão) e imagem em movimento no fundo da tela, por 
trás do texto, podendo ser um vídeo curto ou uma animação. Tal característica (movimento numa camada atrás do texto) está presente também ao longo de todas as reportagens pesquisadas. A presença do movimento é fundamental nesse tipo de narrativa, em que a quantidade de caracteres é muito maior do que no texto noticioso habitual do webjornalismo.

A estratégia de conferir movimento a textos muito longos pode ter o objetivo de manter a atenção do usuário, bem como direcionar seu olhar a elementos na tela em momentos determinados. No webdesign, tal técnica denomina-se parallax scrolling. Conforme Frederick (2013), o parallax scrolling "permite que múltiplos fundos de tela numa página se movimentem simultaneamente em velocidades diferentes para criar uma percepção 3D” (FREDERICK, 2013, p. 18).

No Brasil, o parallax scrolling ainda é pouco utilizado em reportagens, mas em outros países já é um elemento presente em textos longos, como é o caso de Snow Fall, grande reportagem multimídia publicada em 2012 pelo The New York Times que narra, com o apoio de elementos multimídia, a história de esquiadores que foram surpreendidos numa avalanche nos Estados Unidos. Snow Fall ganhou um Pulitzer por sua "narrativa evocativa" e "integração hábil de elementos multimídia" (THE PULITZER PRIZES, 2013).

Outra característica do layout do TAB é o fato de se enquadrar no chamado design responsivo (ZEMEL, 2012), que tem por objetivo adequar as informações ao dispositivo em que o usuário estiver utilizando no momento de acesso (seja computador, smartphone, TV digital, entre outros), de maneira que seja possível a leitura em quaisquer aparelhos sem distorções no tamanho de fontes e objetos, por exemplo. O design responsivo é essencial para conteúdos pensados para o acesso via dispositivos móveis, como é o caso do TAB. A ilustração a seguir exemplifica como funciona o design responsivo:

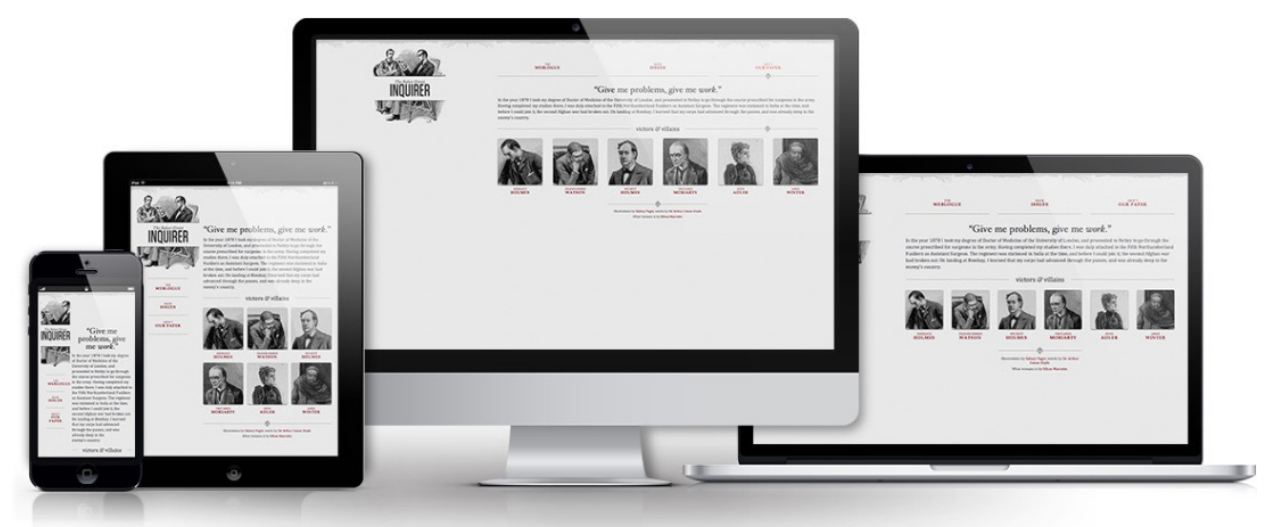

Figura 4. Layout com design responsivo em diferentes dispositivos Fonte: Zonato (2013)

$130 \frac{\text { Comunicação \& Inovação, PPGCOM/USCS }}{\text { v. 17, n. } 35 \text { (121-134) set-dez } 2016}$ 
O conteúdo, como visto na Figura 4, é visualizado de formas ligeiramente distintas em diferentes dispositivos, mas sem perda de informações. O layout é fluído, a fim de que a leitura seja possibilitada em aparelhos com tamanhos de tela diferentes. Já no caso de um layout fixo feito para um site, por exemplo, não haveria a possibilidade de adaptações no tamanho da fonte e na disposição de imagens e ilustrações, o que provocaria distorções e consequente desconforto ou até impossibilidade de leitura. As reportagens do TAB são feitas seguindo o design responsivo, algo que pôde ser comprovado neste trabalho ao se testar a visualização de todas as reportagens no computador, smartphone e tablet.

Tanto o layout responsivo quanto o parallax scrolling podem ser vistos como novos elementos gráficos utilizados nas reportagens do TAB, que auxiliam na construção de uma narrativa jornalística diferenciada. Ambos são bastante recentes e só foram possíveis graças aos avanços técnicos (como o advento da linguagem HTML5) na construção de sites, ocorridos há pouco mais de cinco anos (LONGHI, 2014). Num cenário positivo, tais recursos podem vir a se firmar como características comuns a textos jornalísticos longos na web.

\section{Considerações finais}

Este trabalho exploratório buscou compreender os elementos que ajudam a construir a narrativa do $\mathrm{TAB}$, considerada um exemplo de reportagem do gênero multimídia, que herda algumas características da grande reportagem do impresso (LONGHI, 2014), mas que se enriquece em termos informacionais por apresentar recursos multimídia interativos e hipertextuais. Assim, considera-se o TAB um dos exemplos de produtos midiáticos que mostra ser possível haver narrativas novas no webjornalismo, mais aprofundadas em seu conteúdo e originais em sua forma.

$\mathrm{O}$ texto do TAB se enquadra em estilo, profundidade e tamanho no gênero da reportagem, sem se prender às amarras da pirâmide invertida e do lead. Parece também não se prender ao hipertexto noticioso padrão, no qual, em formato de rizoma, a informação é apresentada em diversas notícias hiperlinkadas entre si. Entretanto, o leitor de uma reportagem do TAB certamente não está fadado a experimentar, por conta da quase ausência de links externos, somente a leitura contemplativa (SANTAELLA, 2004), uma vez que o texto é permeado por elementos multimídia e por interatividade. O TAB é, então, uma narrativa hipermidiática, em que "navegar pelo labirinto da hipermídia é já produzir sentido, o que transforma o leitor de hipertexto também num autor" (VENTURA, 2009, p. 78). 
Assim, mesmo que não seja possível, a partir de links do TAB, visitar outros conteúdos na web, o usuário pode construir seu caminho de consumo da informação da maneira que desejar. Se quer ouvir o áudio com o texto, ver os vídeos antes de ler, apenas ler ou apenas jogar, são vários os caminhos possíveis de não linearidade, todos eles internos à estrutura da reportagem. Tanto os elementos multimídia quanto os interativos funcionam como complemento à informação textual, ao mesmo tempo que possibilitam ao usuário o contato com experiências sobre o tema, estabelecendo, assim, uma prática de leitura sinestésica, imersiva, na qual "o infonauta lê, escuta e olha ao mesmo tempo" (SANTAELLA, 2004, p. 182).

A interatividade do TAB é um elemento de destaque, utilizada inclusive como chamariz comercial, mas vale ressaltar que possui caráter limitado, funcionando apenas como interação reativa, automática, em que as possibilidades são determinadas pela interface e não dão lugar à intervenção do usuário. E, por fim, é importante lembrar que alguns aspectos referentes ao layout do TAB mostraram-se marcantes nessa nova narrativa jornalística: da simples automatização de determinadas práticas - como responder a testes e jogos sem a necessidade de se calcular ou marcar algo com lápis e papel - ao design adaptável a diversos dispositivos - de tipo responsivo - e à técnica de parallax scrolling, que aparenta ser benéfica à leitura de textos longos em formatos digitais.

\section{Referências}

THE PULITZER PRIZES. 2013 Pulitzer prizes. 2013. Disponível em: <http://www.pulitzer.org/citation/ 2013-Feature-Writing>. Acesso em: 30 maio 2015.

BRUNS, A. Gatewatching: collaborative online news production. Nova York: Peter Lang, 2005.

CANAVILHAS, J. Jornalismo para dispositivos móveis: informação hipermultimediática e personalizada. In: CILCS - CONGRESO INTERNACIONAL LATINA DE COMUNICACIÓN, 4., 2012, San Cristóbal de La Laguna. Actas... San Cristóbal de La Laguna: Facultad de Ciencias de la Información. 2012.

Webjornalismo: considerações gerais sobre o jornalismo na web. 2011. Disponível em: <http:// www.bocc.ubi.pt/pag/canavilhas-joao-webjornal.pdf>. Acesso em: 1 maio 2015.

Webjornalismo: da pirâmide invertida à pirâmide deitada. 2006. Disponível em: $<\mathrm{http}: / /$ www.bocc. ubi.pt/pag/canavilhas-joao-webjornalismo-piramide-invertida.pdf>. Acesso em: 3 maio 2015. 
CORREIA, M. Adoção de "paywall” cresce e alavanca assinaturas. Observatório da Imprensa, 6. jan. 2015. Disponível em: http://observatoriodaimprensa.com.br/imprensa-em-questao/_ed832_adocao_de_ paywall_cresce_e_alavanca_assinaturas/. Acesso em: 9 ago. 2016.

O jornalismo e os novos meios de comunicação social. Comunicação \& Sociedade, São Paulo, v. 9-10, p. 15-37, 2006

FREDERICK, D. M. The effects of parallax scrolling on user experience and preference in web design. 2013. Disponível em: <http://docs.lib.purdue.edu/cgttheses/27>. Acesso em: 9 ago. 2016.

GRUSZYNSKI, A. C.; CALZA, M. U. Projeto gráfico: a forma de um conceito editorial. In: SCHWAAB, R.; TAVARES, F. M. (Orgs.). A revista e seu jornalismo. Porto Alegre: Penso, 2013. p. 203-220.

JENKINS, H. Cultura da convergência. Tradução Susana Alexandria. São Paulo: Aleph, 2008.

LONGHI, R. O turning point da grande reportagem multimídia. Famecos, Porto Alegre, v. 21, n. 3, p. 897917, 2014

O GLOBO. "NEW YORK TIMES" restringe acesso de funcionários ao seu site apenas a smartphones e tablets. 12 jun. 2015. Disponível em: <http://oglobo.globo.com/sociedade/midia/new-york-times-restringe-acesso-de-funcionarios-ao-seu-site-apenas-smartphones-tablets-16428478>. Acesso em: 9 ago. 2016.

PADILHA, S. Os valores-notícia no webjornalismo. In: ENCONTRO NACIONAL DE PESQUISADORES EM JORNALISMO, 10., 2012, Curitiba. Anais... Disponível em: <http://docplayer.com.br/ 3743451-Os-valores-noticia-no-webjornalismo.html>. Acesso em: 1 fev. 2015.

PEREIRA, F.; ADGHIRNI, Z. O jornalismo em tempos de mudanças estruturais. Intexto, Porto Alegre, v. 1, n. 24 , p. 38-57, 2011.

PRIMO, A. Enfoques e desfoques no estudo da interação mediada por computador. In: CONGRESSO BRASILEIRO DE CIÊNCIAS DA COMUNICAÇÃO, 26., 2003, Belo Horizonte. Anais... São Paulo: Intercom, 2003.

SALAVERRÍA, R. Redacción periodística en Internet. Pamplona: EUNSA, 2005.

SANTAELLA, L. Navegar no ciberespaço: o perfil cognitivo do leitor imersivo. São Paulo: Paulus, 2004.

TUCHMAN, G. A objectividade como ritual estratégico: uma análise das noções de objetividade dos jornalistas. In: TRAQUINA, N. (Org.). Jornalismo: questões, teorias e “estórias”. Lisboa: Vega, 1993. p. 74-90.

UOL. Uol lança o TAB, novo projeto editorial interativo. 13 out. 2014. Disponível em: <http://noticias.uol. com.br/ultimas-noticias/redacao/2014/10/13/uol-lanca-o-tab-novo-projeto-editorial-interativo. htm>. Acesso em: 9 ago. 2016.

VENTURA, M. S. Hipertexto, noticiabilidade e teoria do jornalismo na web. Líbero, São Paulo, v. 12, p. 75-84, 2009. 
ZEMEL, T. Web design responsivo: páginas adaptáveis para todos os dispositivos. São Paulo: Casa do Código, 2012.

ZONATO, T. Responsive web design: reprojetando o site tersis.com.br. 2013. Disponível em: <http://www. tersis.com.br/blog/responsive-web-reprojetando-o-site-tersis-com-br/?doing_wp_cron=14333536 65.3031580448150634765625>. Acesso em: 10 ago. 2016. 